\title{
Characteristics of lactose-free frozen yogurt with K-carrageenan and corn starch as stabilizers
}

\author{
Katarzyna Skryplonek, ${ }^{1 *}$ Marta Henriques, ${ }^{2,3}$ David Gomes, ${ }^{2}$ Jorge Viegas, ${ }^{2}$ Catarina Fonseca, ${ }^{2}$ \\ Carlos Pereira, ${ }^{2,3}$ Izabela Dmytrów, ${ }^{1}$ and Anna Mituniewicz-Małek ${ }^{1}$ \\ ${ }^{1}$ West Pomeranian University of Technology, Faculty of Food Sciences and Fisheries, Department of Dairy Technology and Food Storage, \\ Papieża Pawła VI street 3, 71-459 Szczecin, Poland \\ ${ }^{2}$ Polytechnic Institute of Coimbra, College of Agriculture, Department of Food Science and Technology, Bencanta, PT-3045-601 Coimbra, Portugal \\ ${ }^{3}$ Research Center for Natural Resources, Environment and Society (CERNAS), College of Agriculture, Polytechnic Institute of Coimbra, Bencanta, \\ PT-3045-601 Coimbra, Portugal
}

\section{ABSTRACT}

Frozen yogurt is a type of dairy product that is considered to be a more healthful alternative to conventional ice cream due to its lower fat content and the presence of viable lactic acid bacteria. Lactose-free products are a growing trend in the dairy industry, and lactose-free yogurts and ice creams can both be found on the market. However, lactose-free frozen yogurt has not yet reached the market. In this study, we aimed to investigate the effect of adding $\kappa$-carrageenan $(0.05$, 0.1 , and $0.15 \%$ ) and corn starch $(1,2$, and $3 \%)$ on acidity, texture, viscosity, overrun, melting properties, color attributes, and sensory characteristics of lactosefree frozen yogurts. Lactose was reduced by enzymatic hydrolysis during the fermentation process. The effectiveness of the hydrolysis was measured by HPLC, and lactose was reduced to $0.05 \%$ after $80 \mathrm{~min}$ of incubation with the enzyme. The addition of stabilizers did not change overrun and melting properties of frozen yogurt, but it did affect $\mathrm{pH}$, titratable acidity, and color parameters. The product with $0.15 \%$ k-carrageenan had the highest hardness and stickiness values. Moreover, $\kappa$-carrageenan had a positive effect on sensory attractiveness of lactose-free frozen yogurt, and it reduced the coarse texture in comparison with the control without stabilizers. A lactose-free frozen yogurt with good quality and nutritional characteristics was produced, particularly with the use of $\kappa$-carrageenan as stabilizer. Key words: frozen yogurt, lactose hydrolysis, corn starch, k-carrageenan

\footnotetext{
Received March 1, 2019.

Accepted April 24, 2019.

*Corresponding author: katarzyna.skryplonek@zut.edu.pl
}

\section{INTRODUCTION}

Frozen yogurt, also referred to as yogurt ice cream, is a frozen dessert made from milk fermented with the use of yogurt starter bacteria (Lactobacillus delbrueckii ssp. bulgaricus and Streptococcus thermophilus). It contains at least $2.7 \%$ milk protein and no more than $10 \%$ milk fat, and it has a titratable acidity of $0.3 \%$ lactic acid, at minimum. The product may contain sweeteners, flavors, colorants, stabilizers, and emulsifiers (FAO/ WHO, 2003). In recent years, consumers have become increasingly aware of the role of balanced diets in maintaining good physical condition, and frozen yogurt is viewed as a more healthful alternative compared with conventional ice cream. Frozen yogurt combines the good sensory attributes of a frozen dessert with nutritional benefits, such as a low fat content and the presence of viable bacteria, and this product is present on the market worldwide (Akin et al., 2007; Isik et al., 2011). Lactic acid bacteria in frozen yogurt are reportedly able to survive for up to $60 \mathrm{wk}$ in storage (Lopez et al., 1998). Moreover, frozen yogurt may also be a good carrier for probiotic bacteria (Ahmadi et al., 2014; Rezaei et al., 2014; Abdelazez et al., 2017).

Lactose is a disaccharide composed of glucose and galactose combined with a $\beta-1 \rightarrow 4$ glycoside linkage. It is present only in milk and milk products, and its content in bovine milk is $4.8 \%$ on average (Gänzle et al., 2008). In ice cream production, lactose can be a problematic component due to its low solubility in comparison with other disaccharides. At ambient temperature, the solubility of lactose is only about $20 \%$ that of sucrose. Thus, in supersaturated solutions, lactose crystallization may occur. During the freezing of an ice cream mix, the content of free water decreases, lactose concentration increases, and crystallization takes place. When the ice cream mix is frozen rapidly, the lactose crystals are too small to be detectable in the mouth. However, when 
the freezing time is long, the crystals may be large enough to cause a rough or gritty sensation known as sandiness (Gänzle et al., 2008). Another disadvantage of lactose in dairy desserts is related to its low sweetness, which is approximately $20 \%$ that of sucrose. Glucose and galactose resulting from lactose hydrolysis are sweeter than lactose and can thereby increase the sweetness of lactose-free dairy products (Adhikari et al., 2010). Aside from the technological aspects, the presence of lactose is a factor limiting consumption of dairy products by consumers with problems digesting it. Lactose is hydrolyzed to glucose and galactose by lactase ( $\beta$-galactosidase) enzyme in the small intestine, but the activity of this enzyme is low in approximately $70 \%$ of the adult population worldwide. Consequently, these individuals cannot properly digest lactose. This disorder is referred to as lactose intolerance, which manifests with symptoms of gut discomfort, such as gas, bloating, and diarrhea. However, the degree of lactose intolerance varies and small doses of lactose are often very well tolerated (Brown-Esters et al., 2012). To tackle technological aspects and to meet the demand of consumers with lactose intolerance, the food industry provides a wide range of lactose-free or lactose-reduced products. The most common method for reducing the content of this disaccharide is lactose hydrolysis by addition of the enzyme $\beta$-galactosidase. Lactase is currently one of the most important enzymes used in food processing, and the market for lactose-hydrolyzed dairy products has developed intensively (Messia et al., 2007; Harju et al., 2012). A large amount of literature exists on lactose-free ice creams and yogurts, but a need remains to design lactose-free frozen yogurt.

For that reason, we aimed to produce frozen yogurt with enzymatically hydrolyzed lactose in this study. We also investigated the effects of 2 stabilizers, corn starch and $\kappa$-carrageenan, on quality characteristics of the product and analyzed select physicochemical, rheological, and sensorial attributes.

\section{MATERIALS AND METHODS}

\section{Materials}

Whole milk, cream, skim milk powder, sucrose, and corn starch were purchased at a local market. к-Carrageenan Carra Gel MCH 5308 was supplied by Formulab Aditivos Alimentares Lda (Maia, Portugal). Ha-Lactase enzyme and a freeze-dried yogurt starter culture (YF-L903) with traditional composition ( $L$. delbrueckii ssp. bulgaricus and S. thermophilus) were supplied by Chr. Hansen (Hørsholm, Denmark). All the chemical reagents used were analytical grade.

\section{Frozen Yogurt Production}

The production of lactose-free frozen yogurt was conducted at the dairy pilot plant at College of Agriculture of the Polytechnic Institute of Coimbra according to the diagram presented on Figure 1.

Whole milk (3.5\% fat, $10.2 \%$ milk solids not fat [MSNF]), cream (35\% fat, 6.8\% MSNF), and skim milk powder ( $1 \%$ fat, $97 \%$ MSNF) were combined in calculated proportions to obtain $5 \%$ fat and $12 \% \mathrm{MSNF}$ in the mixture. These values were adjusted based on preliminary studies, and the same values of fat and MSNF in frozen yogurt preparation were chosen by Hameed et al. (2015). Then, sucrose (6.5\% of the mixture) was added, and the mixture was heated and blended with a home-type blender. The sugar content of the mixture was lower than that suggested in the literature. According to Marshall (2003), the typical range of sugar content in frozen yogurt is 10 to $14 \mathrm{~g} / 100 \mathrm{~g}$. We added less sugar in our formulations in anticipation of the fact that galactose and glucose resulting from lactose hydrolysis would contribute to the sweetness of the final product. Subsequently, the mixture was pasteurized at $95^{\circ} \mathrm{C}$ for $5 \mathrm{~min}$, following the enzyme manufacturer's recommendations. The next production step was addition of a hydrocolloid, $\kappa$-carrageenan $(0.05,0.1$, or $0.15 \%)$ or corn starch $(1,2$, or $3 \%)$. These components were selected from a wide range of stabilizers tested in a preliminary study, and the objective of their use was to improve the melting resistance and texture of the product. All batches were produced in amounts of $1 \mathrm{~L}$ of yogurt. Corn starch was dissolved in the cold mixture, and $\kappa$-carrageenan after heating the mixture. Then, the mixtures were homogenized using a T25 Ultra-Turrax (IKA Werke, Staufen, Germany). We chose gentle homogenization conditions $(8,000 \mathrm{rpm}$ for $10 \mathrm{~s})$ to avoid deterioration of the additives. The mixes were then heated to $44^{\circ} \mathrm{C}$. The hydrolysis of lactose was performed in accordance with the manufacturer's procedure. Ha-Lactase was added to the mixture at 2.5 $\mathrm{g} / \mathrm{L}$, which corresponds to 2,500 natural lactase units per liter. After $30 \mathrm{~min}$ of incubation at $44^{\circ} \mathrm{C}$, the freezedried yogurt starter culture was added $(0.006 \mathrm{~g} / \mathrm{L})$. The enzyme was added $30 \mathrm{~min}$ prior to the starter culture addition to ensure sufficient time for lactose hydrolysis, but the reaction still occurred simultaneously with the fermentation process. When the $\mathrm{pH}$ of the mixture dropped to 5.5, the enzyme was inactivated. As stated in a preliminary study, the $\mathrm{pH}$ decreased to this value after approximately $2.5 \mathrm{~h}$ of fermentation. According to the enzyme supplier, under optimum conditions, $2.5 \mathrm{~h}$ is sufficient time to reduce lactose content by almost $100 \%$. Nevertheless, to ensure that the product 
is lactose free, we extended the time by an additional 30 min. Fermentation continued until the $\mathrm{pH}$ dropped to $4.6 \pm 1(\sim 4 \mathrm{~h})$. Then yogurts were cooled at room temperature for about $3 \mathrm{~h}$ and aged in refrigerated conditions $\left(4 \pm 1^{\circ} \mathrm{C}\right)$ overnight. The lactose-free yogurts were frozen in a home-type ice cream maker (Klarstein, Berlin, Germany). The freezing time was $1 \mathrm{~h}$. The frozen yogurts were then filled into plastic containers and stored at $-18 \pm 1^{\circ} \mathrm{C}$ overnight.

\section{Assessment of Lactose Hydrolysis}

During the process of lactose hydrolysis, the sugar content (lactose, glucose, and galactose) was monitored. Standards for all saccharides present in the samples (lactose, sucrose, glucose, and galactose) were used to determine their retention time. The concentration of saccharides was measured by HPLC. Samples were taken from the mixtures before enzyme addition (time 0) and then every $20 \mathrm{~min}$. To inactivate the en- zyme, the samples were heated in a microwave oven at the time of collection. Two grams of each sample was transferred to a $25-\mathrm{mL}$ volumetric flask, and 2.5 $\mathrm{mL}$ of acetonitrile was added to precipitate proteins. The mixture was made up to $25 \mathrm{~mL}$ with deionized water and then filtered through a $0.45-\mu \mathrm{m}$ polytetrafluoroethylene syringe membrane. Chromatographic separation was performed at $20^{\circ} \mathrm{C}$ in a Jasco HPLC System (Jasco International Co., Tokyo, Japan), which consisted of a carbohydrate column $\left(\mathrm{NH}_{2}\right)$, a Perkin Elmer LC-100 column oven (Perkin Elmer, Waltham, MA), a high-pressure pump (Jasco PU-980), and a Jasco 830-RI detector. The external interface (HerculeLite) for data acquisition was coupled to the system, and chromatographic data were recorded and processed with Jasco-Borwin software (JMBS Developments, Le Fontanil, France). The mobile phase was acetonitrile: water (80:20), and the flow rate was $2.0 \mathrm{~mL} / \mathrm{min}$. Retention time was $16 \mathrm{~min}$ for lactose and $7 \mathrm{~min}$ for glucose plus galactose.

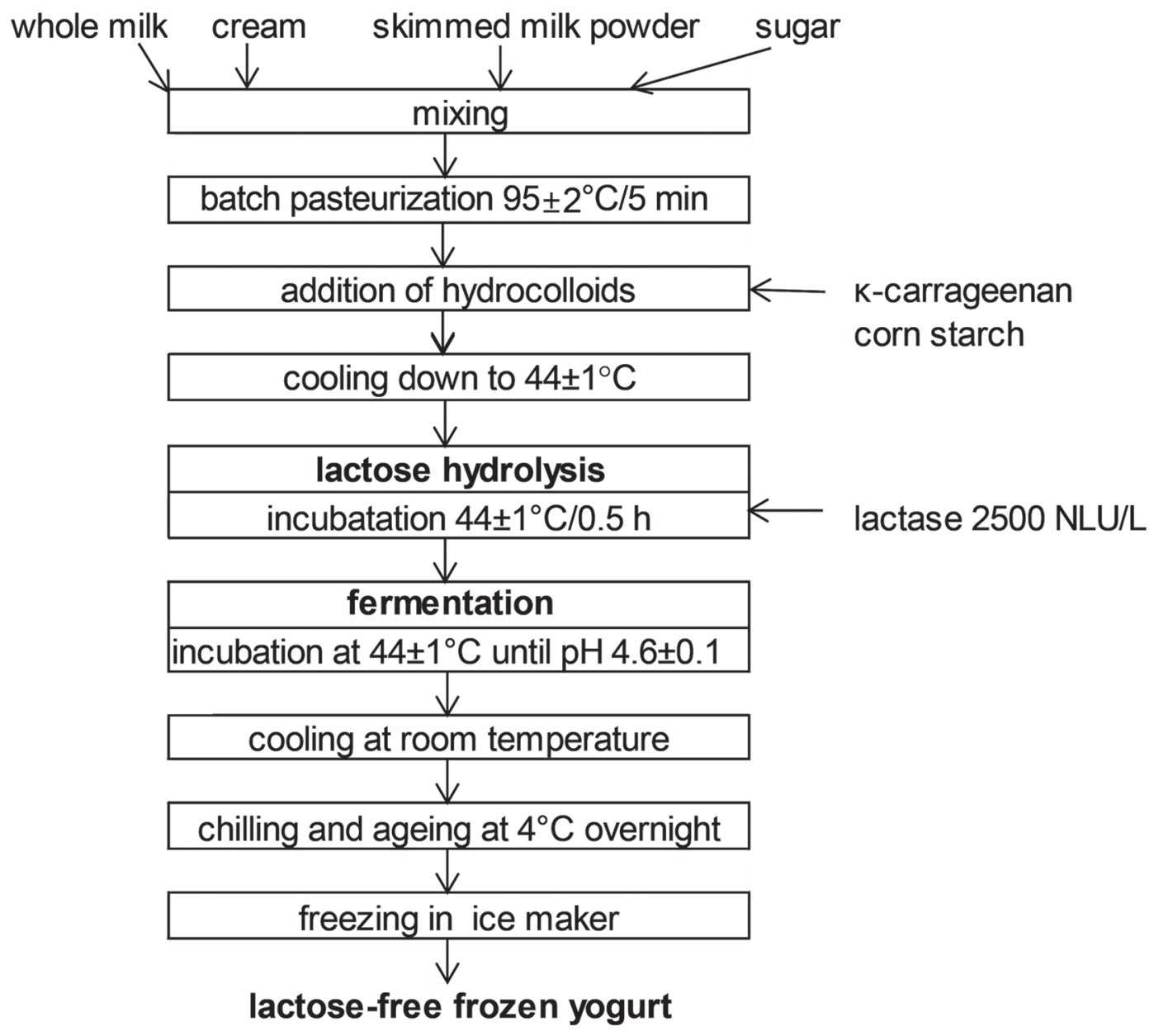

Figure 1. Lactose-free frozen yogurt production flowchart. NLU = natural lactase units. 


\section{Yogurt Analyses}

The chemical composition, $\mathrm{pH}$, and lactic acid content were measured in control yogurt without corn starch or $\kappa$-carrageenan. The analyses were performed in accordance with Official Analytical Methods (AOAC International, 1997) and Portuguese Standards Methods (IPQ, 1990). Protein content was determined by the Kjeldahl method and the fat content by the Gerber method. Total solids were determined by drying at $105^{\circ} \mathrm{C}$ for $120 \mathrm{~min}$. Ash content was determined after incineration of dry samples in an electric muffle furnace (model LE 4/11/R6, Nabertherm, Lilienthal, Germany). The $\mathrm{pH}$ was evaluated with a $\mathrm{pH}$ meter (model HI9025, Hanna Instruments, Ronchi di Campanile PD, Italy). Titratable acidity, expressed as a percentage of lactic acid, was assessed by titration using $0.1 \mathrm{~N} \mathrm{NaOH}$ solution.

\section{Frozen Yogurt Analyses}

$\mathrm{pH}$ and lactic acid content were evaluated in melted samples with the same methods as in fresh yogurt.

The texture analysis was performed by a cycle test with the use of texture analyzer model TA.XT Express Enhanced (Stable Micro Systems, Godalming, UK). The test included the measurement of hardness (the peak force during the penetration of the sample) and stickiness (the negative peak force during the withdrawal of the probe), and it was run with a penetration distance of $25 \mathrm{~mm}$ at $1 \mathrm{~mm} / \mathrm{s}$ test speed using a cylindrical 6-mm-diameter acrylic probe (Milani and Koocheki, 2011). Viscosity was measured by a rotational viscometer (Brookfield Viscometer model DV II, Brookfield Engineering Inc., Middleboro, MA) at a rotation rate of $20 \mathrm{rpm}$ with spindle number 5 . The volume of sample was $150 \mathrm{~mL}$, and the immersion depth of the spindle was constant throughout the test. To simulate the conditions during ice cream consumption, the assessments were carried out at ambient conditions $\left(20 \pm 1^{\circ} \mathrm{C}\right)$.

Overrun, defined as the increase in the volume of the frozen yogurt due to air incorporation, was measured by comparing the weight (wt) of an equal volume of yogurt before and after freezing. Calculations were made using the following formula (Akin et al., 2007):

Overrun $(\%)=\frac{\text { wt of yogurt }- \text { wt of frozen yogurt }}{\text { wt of frozen yogurt }} \times 100$.

Meltdown rate was determined according to the method proposed by Milani and Koocheki. (2011) with some modifications. A 30-g scoop of frozen yogurt was placed on a stainless-steel screen with openings of $1 \times 1 \mathrm{~mm}$, located on top of a beaker. After 45 min at $20 \pm 2^{\circ} \mathrm{C}$, the weight of the collected sample in the beaker was recorded. Meltdown rate was expressed as the percentage of the weight of the initial frozen yogurt scoop:

$$
\text { Meltdown rate }(\%)=\frac{\text { wt of melted sample }}{\text { wt of scoop }} \times 100 \text {. }
$$

During the measurement of the meltdown rate, the time of first drop appearance (first dripping time) was also recorded.

The color parameters $L^{*}$ (lightness) $a^{*}$ (red-green color), and $\mathrm{b}^{*}$ (yellow-blue color) were determined using the $\mathrm{L}^{*} \mathrm{a}^{*} \mathrm{~b}^{*}$ CIELAB system on the surface of the frozen yogurts with a colorimeter Minolta Chroma Meter (model CR-200B, Konica Minolta, Tokyo, Japan), previously calibrated with the white standard plate.

Sensory quality was estimated by consumer-based ranking test according to ISO Standard 13299 (ISO, 2016). Twenty participants, including men and women of various ages, participated in the test. We selected only consumers who claimed to regularly eat frozen dairy desserts. The participants were asked to rank frozen yogurt samples from the best to the worst sensory quality. Each sample was coded using a 3-digit random number. The test was performed in 2 parts. In the first part, a control sample and samples with corn starch were evaluated, and in the second, a control sample and samples with $\kappa$-carrageenan were assessed.

\section{Statistical Analysis}

The analyses were performed in triplicate, and texture was measured with 5 repetitions. Mean values and standard deviations were calculated. The results were statistically analyzed using Statistica 13.1 Software (StatSoft Inc., Tulsa, OK) at the significance level $P$ $<0.05$. The mean values of the quality properties were compared by the honestly significant difference (HSD) test and the influence of the composition on analyzed characteristics was evaluated by ANOVA. For the interpretation of sensory evaluation by ranking test, the Friedman test was used.

\section{RESULTS AND DISCUSSION}

\section{Lactose Hydrolysis Effectiveness}

During the incubation of yogurt mixtures with lactase, we observed a gradual decrease of lactose and gradual increases of glucose and galactose concentrations (Figure 2). The lactose content before enzyme addition was $4.4 \%$, and during the first $20 \mathrm{~min}$ of incubation, it dropped to $1.5 \%$ (a $66 \%$ decrease). When yogurt started culture was added, 30 min after lactase 
addition, bacterial fermentation caused a further decrease in the lactose concentration. The lactose content was $0.05 \%$ after $80 \mathrm{~min}$, and it was undetectable after 120 min. A simultaneous increase in the concentration of monosaccharides was observed. At the end of incubation, we noted that the content of monosaccharides decreased, presumably because of bacterial fermentation of these sugars. The results confirmed that a $100 \%$ reduction of lactose content was achieved and the frozen yogurt obtained was lactose free. In the study of Vénica et al. (2016), who added $\beta$-galactosidase enzyme simultaneously with yogurt culture, the lactose content of the yogurt decreased by $78 \%$. Wolf et al. (2015) also added enzyme with yogurt starter culture and obtained a reduction of lactose ranging from 75 to $78 \%$. These authors also found that the lactose hydrolysis influenced the production of volatile compounds in yogurt. Moreira et al. (2017) performed lactose hydrolysis in pasteurized milk, which was then heated to $70^{\circ} \mathrm{C}$ to inactivate the enzyme prior to yogurt being made. The resultant yogurt had a lactose content of less than $0.10 \%$. Raza et al. (2018) also hydrolyzed lactose in milk before yogurt production and obtained a lactose level of $1.45 \%$ in hydrolyzed yogurt. Messia et al. (2007) obtained 0.5-0.6\% lactose in semiskim lactose-hydrolyzed milk. The studies conducted by Chen at al. (2002) and Vénica et al. (2016) showed in addition to reducing the disaccharide content, lactose hydrolysis led to the production of galacto-oligosaccharides (GOS), which are prebiotics that may positively affect the viability of lactic acid bacteria. The enzyme $\beta$-galactosidase simultaneously with glucose and galactose releasing, can produce some amounts of GOS (Vénica et al., 2016). These GOS may contribute to better survivability of lactic acid bacteria in lactose-free frozen yogurt in comparison with normal frozen yogurt. Moreover, GOS act as a fat replacement

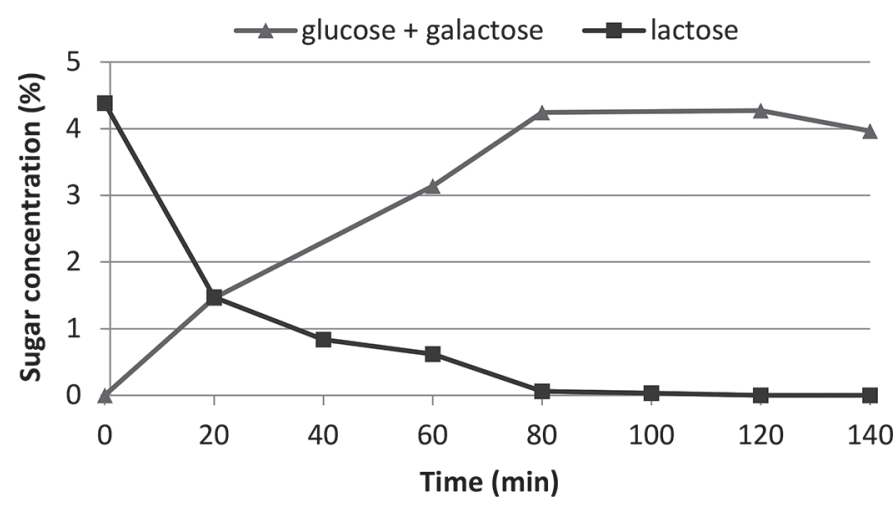

Figure 2. Concentrations of lactose and reducing sugars (glucose + galactose) during the incubation of frozen yogurt mixture. component and improve the texture of frozen desserts (Singla and Chakkaravarthi, 2017).

\section{Yogurt Composition}

The chemical composition of control lactose-free frozen yogurt was $19.06 \pm 0.16 \%$ of total solids, $4.8 \pm$ $0.1 \%$ of fat, $3.37 \pm 0.08 \%$ of protein, and $0.68 \pm 0.03 \%$ of ash. The $\mathrm{pH}$ acidity was $4.36 \pm 0.01$, and titratable acidity was estimated as $0.818 \pm 0.002 \%$ of lactic acid. The measurements were performed directly before freezing, after overnight maturation of yogurt. The content of total solids and fat reflected the composition of the frozen yogurt mixture. The $\mathrm{pH}$ of control yogurt before freezing was lower than that of frozen yogurt, while lactic acid content was slightly higher.

\section{Effect of Stabilizers}

The fat content of frozen yogurt ranges from 3.5 to $6 \%$ (Marshall, 2003), which is lower than in typical ice cream. A low fat content affects quality attributes such as viscosity, creaminess, hardness, melting behavior, and flavor (Milani and Koocheki, 2011). Therefore, the use of stabilizers is normally required. These additives improve viscosity and air incorporation and can retard melting of frozen dairy desserts. Moreover, by forming weak gels, hydrocolloids used as stabilizers inhibit the growth of ice crystals (recrystallization) during storage by preventing the migration of water from small to large ice crystals (Marshall, 2003; Goff and Hartel, 2004). During the preliminary study, we analyzed a range of stabilizers used in frozen dairy dessert production (xanthan gum, guar gum, locust bean gum, and their mixtures; $\kappa$-carrageenan; corn starch; and Simplesse, CP Kelco, Atlanta, GA). Our choice of stabilizers was based on quality attributes and consumer preference (data not included). Although corn starch is not a typical stabilizer used in ice cream production, the preliminary study showed that it positively affected sensory assessment. In addition, corn starch has the advantages of a low price and high availability. Inoue et al. (1998) also analyzed the use of corn starch in ice cream-type frozen yogurt production and reported that $\mathrm{pH}$ and lactic acid content were stable during the 6-mo storage period. However, the viability of yogurt bacteria declined during storage. In contrast to corn starch, $\kappa$-carrageenan is a typical stabilizer used in dairy technology. It is a hydrocolloid derived from red seaweeds and is effective at low concentrations of approximately 0.3\% (Pei and Schmidt, 2010). $\kappa$-Carrageenan can form complexes with casein and thereby improve a product's structure and stability (Soukoulis et al., 2008; BahramParvar et al., 2013). 
Table 1. Melting properties of lactose-free frozen yogurts with different levels of stabilizers

\begin{tabular}{llcc}
\hline Product & Code & $\begin{array}{c}\text { Melting rate } \\
(\%)\end{array}$ & $\begin{array}{c}\text { First drop } \\
(\text { min })\end{array}$ \\
\hline Control & C & $63 \pm 5^{\mathrm{a}}$ & $4.28 \pm 1.60^{\mathrm{a}}$ \\
Carrageenan 0.05\% & CR 0.05 & $61 \pm 4^{\mathrm{a}}$ & $6.28 \pm 0.52^{\mathrm{a}}$ \\
Carrageenan 0.1\% & CR 0.1 & $50 \pm 9^{\mathrm{a}}$ & $6.28 \pm 2.15^{\mathrm{a}}$ \\
Carrageenan 0.15\% & CR 0.15 & $46 \pm 8^{\mathrm{a}}$ & $5.62 \pm 1.93^{\mathrm{a}}$ \\
Corn starch 1\% & CS 1 & $54 \pm 8^{\mathrm{a}}$ & $5.72 \pm 2.98^{\mathrm{a}}$ \\
Corn starch 2\% & CS 2 & $56 \pm 7^{\mathrm{a}}$ & $4.17 \pm 0.72^{\mathrm{a}}$ \\
Corn starch 3\% & CS 3 & $52 \pm 3^{\mathrm{a}}$ & $3.72 \pm 1.25^{\mathrm{a}}$ \\
\hline
\end{tabular}

${ }^{a}$ Different superscripts indicate statistically significant differences $(P<0.05)$.

\section{Melting Properties}

The data presented in Tables 1 and 2 reveal that the addition of corn starch or $\kappa$-carrageenan did not significantly influence the melting properties of the samples. However, we observed that products with stabilizers had a slightly lower melting rate than the control, and samples containing 0.05 and $0.1 \%$ of $\kappa$-carrageenan had the longest period of time before the product started to drip. The increase of hydrocolloid content results in a decreasing melting rate of frozen desserts, and the improvement in melting quality. This is related to the water-holding capacity of stabilizers. In addition, higher overrun of ice creams with stabilizers inhibits heat transfer to the interior of the ice cream (Marshall, 2003; Soukoulis et al., 2008).

The literature includes different values for melting parameters. Guner et al. (2007) produced yogurt ice cream containing up to $20 \%$ of yogurt and found lower melting rates (33.8-42.92\% after 50 min of melting) and a longer first drop time (a range of 15.33-17.66 min). Much higher values of first dripping time of frozen yogurt were obtained by Güven and Karaca (2002) and Rezaei et al. (2014), who reported 27.83 to 32.83 min and 17.2 to $37.7 \mathrm{~min}$, respectively. Melting rate values measured under the same conditions used in our study ranged between 25 and 55\% (El-Nagar et

Table 2. The results of ANOVA test of lactose-free frozen yogurts

\begin{tabular}{lrl}
\hline Parameter & $F$-value & $P$-value \\
\hline pH & 14.8553 & $0.0000^{*}$ \\
\% Lactic acid & 25.0014 & $0.0000^{*}$ \\
Overrun & 2.4203 & 0.0812 \\
First drop & 0.9082 & 0.5166 \\
Melting rate & 2.5515 & 0.0698 \\
Hardness & 6.1896 & $0.0024^{*}$ \\
Stickiness & 7.2226 & $0.0011^{*}$ \\
Viscosity & 79.5522 & $0.0000^{*}$ \\
$\mathrm{~L}^{*}$ & 330.1624 & $0.0000^{*}$ \\
$\mathrm{a}^{*}$ & 74.8182 & $0.0000^{*}$ \\
$\mathrm{~b}^{*}$ & 79.1270 & $0.0000^{*}$ \\
\hline
\end{tabular}

*Statistically significant influence $(P<0.05)$ of product composition on analyzed parameter. al., 2002) and between 30 and 70\% (Isik et al., 2011), and in both cases, the values were consistent with our findings. Nevertheless, the differences found in the literature may be associated with the frozen yogurts having different compositions and methods of production compared with those in our study.

\section{$\mathrm{pH}$ and Titratable Acidity}

The $\mathrm{pH}$ values and lactic acid content are shown in Figure $3 \mathrm{~A}$ and $3 \mathrm{~B}$. The $\mathrm{pH}$ of the products ranged between 4.13 and 4.23 . The lowest $\mathrm{pH}$ value was observed in the control sample, and the addition of $\kappa$-carrageenan or corn starch increased $\mathrm{pH}$ values. However, increasing the stabilizer concentration further did not affect $\mathrm{pH}$. Titratable acidity of all obtained products was similar and ranged between 0.74 and $0.78 \%$ of lactic acid. Only the samples with 1 and $2 \%$ corn starch differed significantly from other products. Higher active and titratable acidity of frozen yogurts compared with yogurt may be explained by constant fermentation activity of lactic acid bacteria during freezing and melting of the frozen yogurt sample.

The literature contains diverse $\mathrm{pH}$ and titratable acidity values of frozen yogurt that are mainly associated with the composition of the products. Guner et al. (2007) obtained frozen yogurt with $\mathrm{pH} 4.54$ to 5.25 and 0.47 to $0.58 \%$ lactic acid. These authors also stated that acidity values exceeding $0.7 \%$ resulted in deterioration of sensory quality of frozen yogurt. Isik et al. (2011) produced frozen yogurt with inulin and isomalt. The $\mathrm{pH}$ of those products ranged between 4.8 and 5.2, and the lactic acid was 0.69 to $0.72 \%$. Milani and Koocheki (2011) observed acidity values similar to our findings. The $\mathrm{pH}$ and lactic acid content in frozen yogurts with various amounts of guar gum and isomalt ranged between 4.3 and 4.7 and between 0.65 and $0.77 \%$, respectively. The higher acidity of our product is due to all formulation mixtures having undergone fermentation; that is, the frozen yogurt was made solely from yogurt. Another reason could be related to the greater intensity of the fermentation process because of 

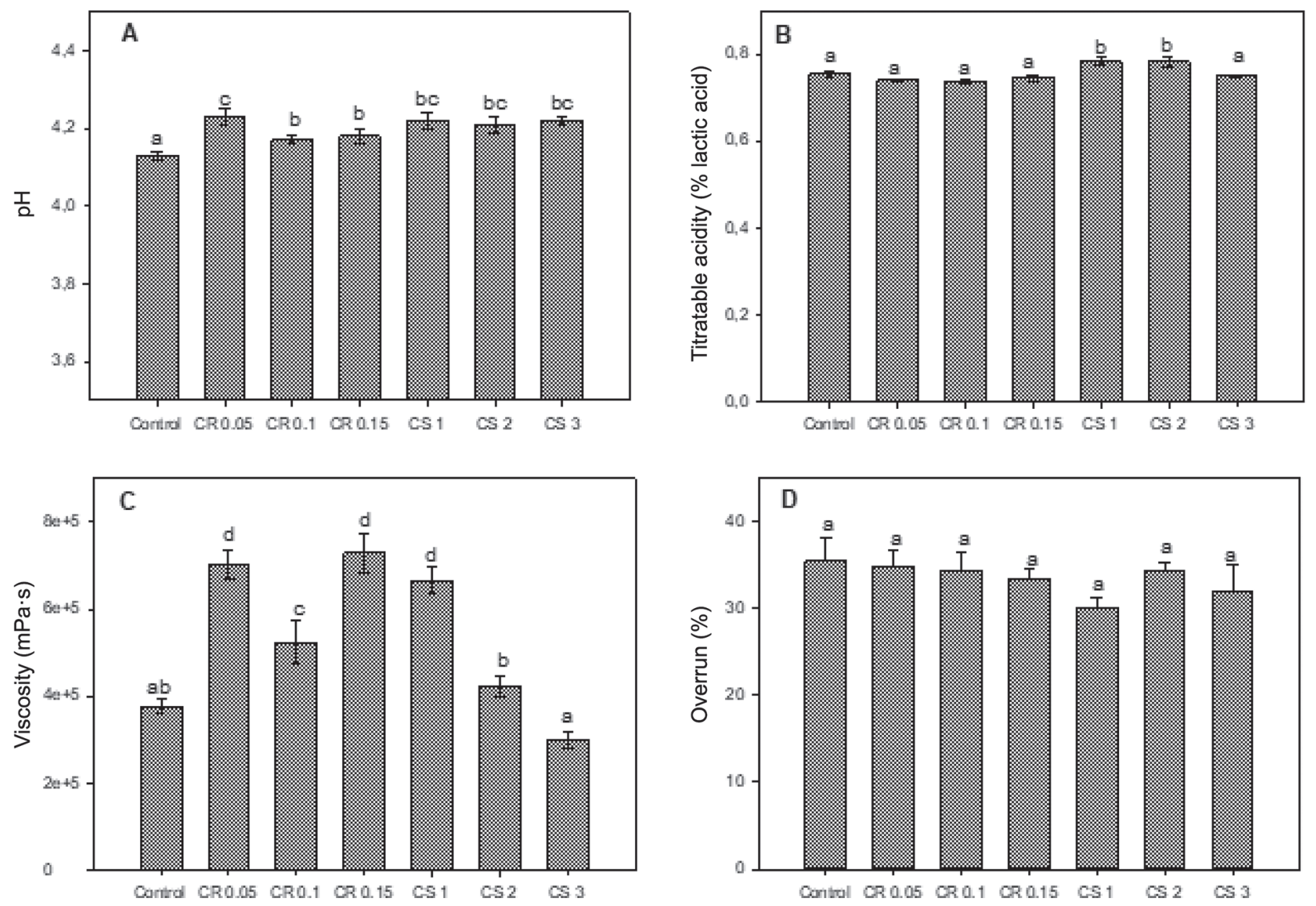

Figure 3. Mean values and SD of (A) pH, (B) titratable acidity (\% lactic acid), (C) viscosity, and (D) overrun of frozen yogurts made with different levels of $\kappa$-carrageenan $(0.05,0.1$, and $0.15 \%$; CR 0.05 , CR 0.1, and CR 0.15) and corn starch (1, 2, and 3\%; CS 1, CS 2, and CS 3). Different letters above bars indicate statistically significant differences among treatments $(P<0.05)$.

the higher availability of glucose resulting from lactose hydrolysis.

\section{Viscosity and Overrun}

The viscosity of the frozen yogurt samples (Figure 3C) depended on the composition and varied widely. Stabilizers increase the viscosity of frozen yogurts by limiting the mobility of water molecules (Moeenfard and Tehrani, 2008; Milani and Koocheki, 2011), and higher viscosity is associated with a more stable fatliquid emulsion and improved melting stability of the product (El-Nagar et al., 2002). Viscosity is also correlated with creaminess and mouthfeel of frozen desserts (BahramParvar et al., 2013). Our results indicate that $\kappa$-carrageenan has a better ability to improve viscosity than corn starch. The concentration of $\kappa$-carrageenan that yielded the best results was $0.05 \%$, which produced a viscosity that was almost as high as in product with
$0.15 \%$ of the stabilizer. The effect of corn starch was less notable; moreover, the 2 and $3 \%$ concentrations of corn starch diminished the rheological characteristics in comparison with the $1 \%$ concentration. Soukoulis et al. (2008) stated that $\kappa$-carrageenan, among other stabilizers, increases the viscosity of frozen yogurt. Milani and Koocheki (2011) improved the viscosity of frozen yogurt by addition of guar gum. Besides typical stabilizers, inulin can also improve the rheological characteristics of frozen yogurt (El-Nagar et al., 2002; Isik et al., 2011; Rezaei et al., 2014). Viscosity of this type of dessert is also positively affected by fat and sugar content (Isik et al., 2011). Guner et al. (2007) found that the use of yogurt instead of milk results in lower viscosity of frozen desserts due to the effect of acidity.

Overrun is one of the most important characteristics of frozen desserts (Marshall, 2003). It affects the sensory attractiveness as well as the price of the product. Aside from increasing the volume of the final prod- 
uct, the incorporation of air into the mix provides a light texture and influences the melting properties of the product (Rezaei et al., 2014). Guner et al. (2007) reported that frozen yogurt has lower overrun than typical ice cream made from milk. Our results showed that overrun, similar to meltdown properties, was not affected by the presence of $\kappa$-carrageenan or corn starch (Table 3) and ranged between 30 and 35\% (Figure 3D). Overrun was not influenced by product composition because it is mainly determined by production conditions. Home-type ice cream makers have a low mixing speed, thus overrun is smaller than in industrial ice cream machines. A similar range of overrun values for frozen yogurts can be found in the literature. Güven and Karaca (2002) noted 22 to 32\% overrun; Guner et al. (2007) reported 27 to 29\%; Milani and Koocheki (2011), 19 to $34 \%$; and Rezaei et al. (2014), 22 to $38 \%$. Moeenfard and Tehrani (2008) stated that overrun of frozen yogurt is positively affected by stabilizers, which prevent air bubbles from collapsing. Akin et al. (2007) found that increasing the sugar content of the mixture makes the structure of ice cream softer and thus facilitates air incorporation and increases overrun.

\section{Hardness and Stickiness}

The structure of frozen dairy products depends on composition (fat, sugars, proteins, stabilizers) and the processing conditions (homogenization, aging, freezing). The texture is strongly related to fat and sugar content. An increase in fat causes an increase in stickiness, and amounts of fat and sugar are inversely related to the hardness of the final product (El-Nagar et al., 2002; Güven and Karaca, 2002; BahramParvar et al., 2013). The values for hardness and stickiness, the main textural attributes of frozen yogurt, varied between samples. The highest values for both parameters were obtained for the product with $0.15 \% \mathrm{\kappa}$-carrageenan, and the lowest for the product with $2 \%$ corn starch (Figure 4 ). The highest hardness value $(0.638 \mathrm{~N})$ of the product with $0.15 \%$ of $\kappa$-carrageenan suggests that the concentration of the stabilizer was too high and resulted in a stronger gel network. Analysis of variance revealed that product composition significantly affected the hardness and stickiness. However, the HSD test showed that despite the differences between samples with different stabilizers, none of the samples with stabilizers differed significantly from the control. Soukoulis et al. (2008), Milani and Koocheki (2011), and BahramParvar et al. (2013) stated that stabilizer addition decreases hardness and increases stickiness of dairy frozen desserts. However, these effects are observed during product storage and are connected with the prevention of ice recrystalliza-

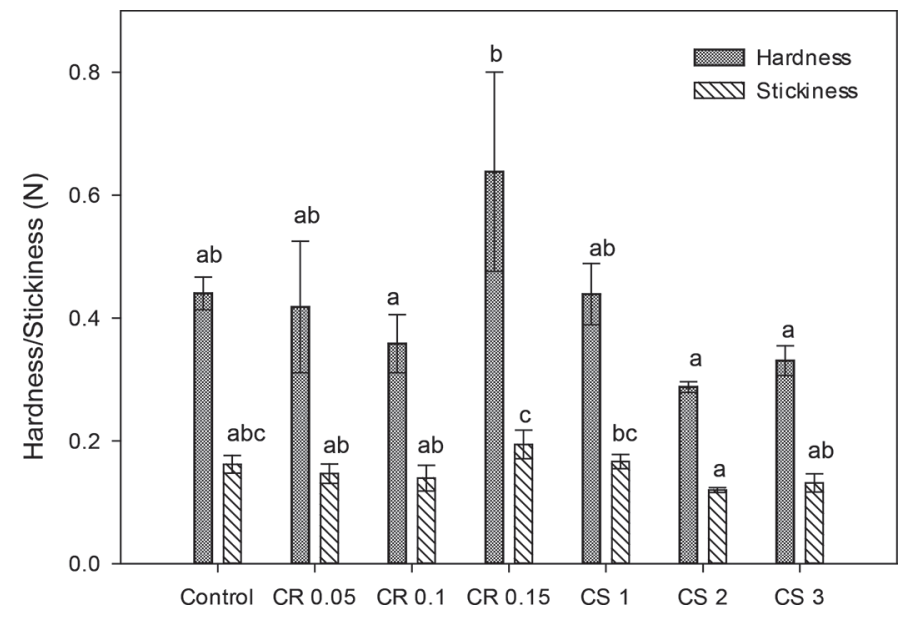

Figure 4. Mean values and SD of textural parameters of lactosefree frozen yogurts. Samples with different levels of $\kappa$-carrageenan $(0.05,0.1$, and $0.15 \%$; CR 0.05 , CR 0.1, and CR 0.15) and corn starch $(1,2$, and $3 \%$; CS 1 , CS 2, and CS 3). Different letters above bars indicate statistically significant differences among treatments $(P<0.05)$.

tion. The effect of hydrocolloids on textural parameters immediately after production is not so distinct because recrystallization is not a factor at this time point.

\section{Color Parameters}

Color is a pivotal aspect in product acceptance by consumers. The use of some additives may distinctly modify color, which may in turn cause consumers to have a negative view of the product. Color parameters are also important in the case of dairy products such as ice cream and frozen yogurts. However, studies concerning this aspect are lacking. The color of frozen yogurt should represent the color of yogurt and be homogeneous. In our study, we did not use color additives, and the final product was expected to be light-colored and creamy in appearance. Measurements made with a colorimeter showed that lactose-free frozen yogurts with either stabilizer used in any concentration had significantly higher values of the $\mathrm{L}^{*}$ parameter, which means that they were brighter than the control lactose-free product. Cais-Sokolińska and Pikul (2006), who analyzed the color of fermented milk, stated that acidity affects the lightness index and an increase in this parameter causes lightness to decline. This finding may explain the lowest lightness values were associated with our control product, which also had the lowest $\mathrm{pH}$ value. The negative values of $\mathrm{a}^{*}$ and positive values of $b^{*}$ indicate green-yellow color characteristics of the frozen yogurts. In the case of samples with stabilizers, the green-yellow color was significantly more intense (Fig- 


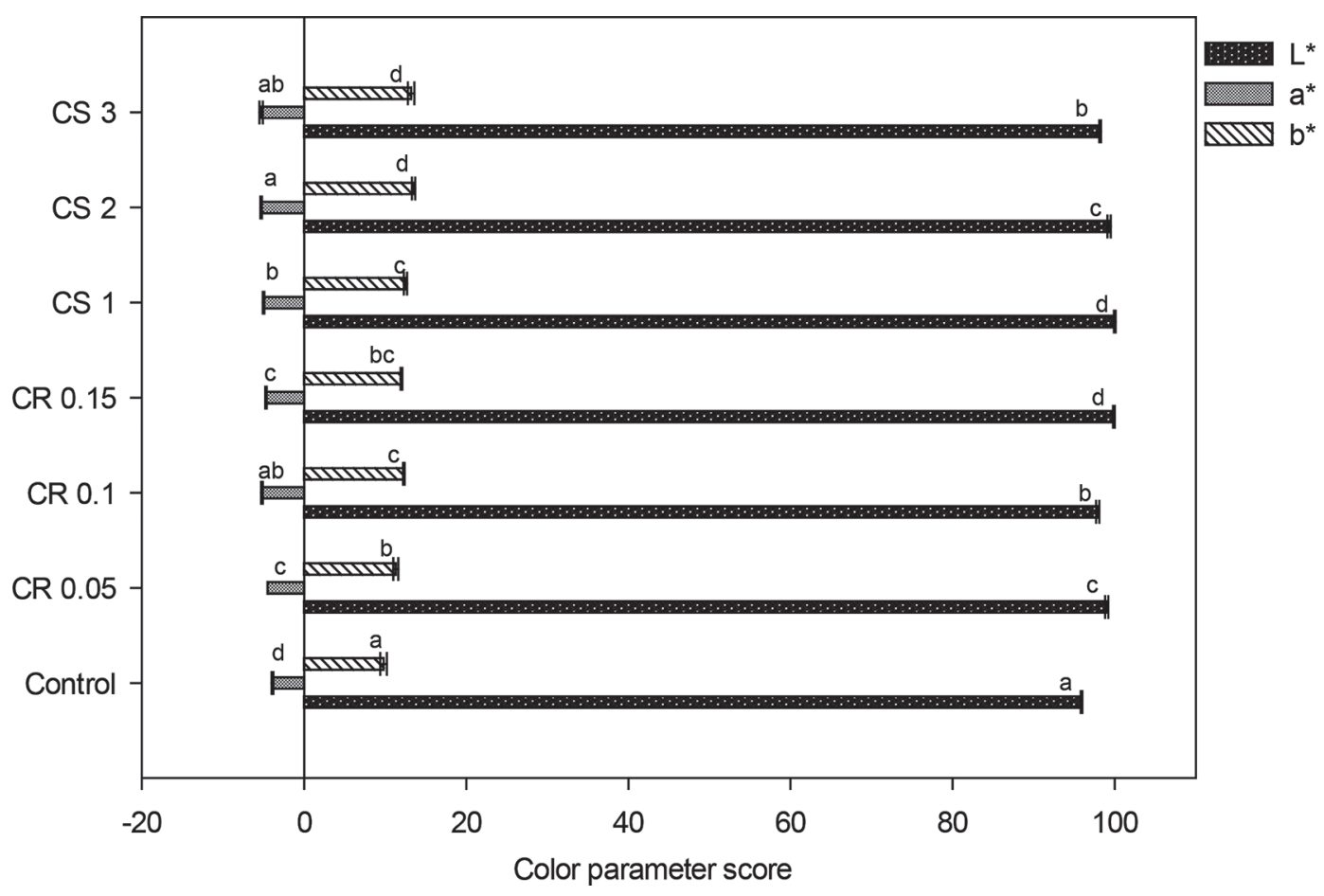

Figure 5. Mean values and SD of color parameters $\left(\mathrm{L}^{*}, \mathrm{a}^{*}, \mathrm{~b}^{*}\right)$ of lactose-free frozen yogurts. Samples with different levels of $\kappa$-carrageenan $(0.05,0.1$, and $0.15 \%$; CR 0.05, CR 0.1, and CR 0.15) and corn starch (1,2, and 3\%; CS 1, CS 2, and CS 3). Different letters in bars indicate statistically significant differences among treatments $(P<0.05)$.

ure 5). These results lead us to conclude that addition of stabilizers significantly affected the color parameters. However, due to the brighter color, which is characteristic of dairy products, the color of the samples should be perceived as natural and attractive.

\section{Sensory Analysis}

The sensory properties of frozen yogurt, such as mouthfeel, creaminess, consistency, and ice crystal perception, are very important factors in consumers' acceptance (Stampanoni et al., 1996). The results of the sensory evaluation for lactose-free frozen yogurt using the ranking test are presented on Figure 6. The participants of the evaluation separately assessed lactose-free frozen yogurts with $\kappa$-carrageenan and corn starch in comparison with the control product. Products containing corn starch did not differ from the control $(P<$ $0.05)$, but samples with $\kappa$-carrageenan had significantly better sensory properties than the control $(P<0.05)$. Products with $\kappa$-carrageenan had a smooth structure, while the control product had a slightly coarse consistency due to the presence of ice crystals that were large enough to be detectable in the mouth. However, products with different $\kappa$-carrageenan amounts did not differ significantly $(P<0.05)$ in the sensory as- sessment. These results indicate that $\kappa$-carrageenan is better able to stabilize the structure of frozen yogurt and to prevent the product from being too hard and having a gritty consistency. The stabilizing effect of $\kappa$-carrageenan in frozen yogurt was reported by Soukoulis et al. (2008), and a positive effect on the structure of soft-serve ice cream due to the emulsifying properties of k-carrageenan was reported by Vega and Goff (2005). The addition of stabilizers is known to inhibit the recrystallization process and to prevent the formation of perceptible ice crystals in frozen yogurt, therefore contributing to its creamier texture (Moeenfard and Tehrani, 2008; Isik et al., 2011). The presence of a coarse consistency in frozen yogurts may be connected with low fat content, which was on the order of $5 \%$. The concentration of fat affects the sensory characteristics of frozen desserts. Reducing the fat in ice cream mix leads to the product being less creamy and having lower mouth-coating properties, which in turn enhances the perception of ice crystals in ice cream (Stampanoni et al., 1996; Guinard et al., 1997). In their study, ElNagar et al. (2002) also prepared low-fat frozen yogurt with $5 \%$ fat content. The product had poor consistency, characterized as hard, icy, coarse, and gritty, and a low fat content was indicated as the reason for these drawbacks. 
A

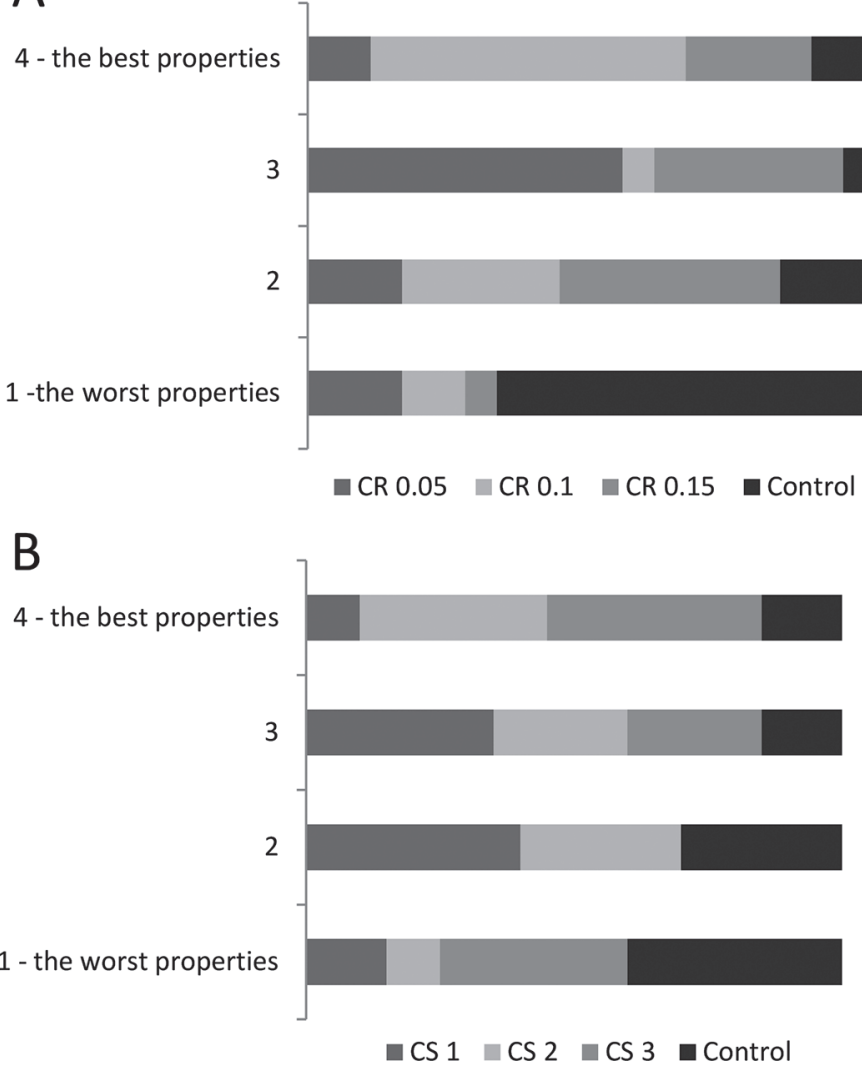

Figure 6. The results of sensory analysis by ranking test of frozen yogurt with different levels of $\kappa$-carrageenan $(0.05,0.1$, and $0.15 \%$; CR 0.05 , CR 0.1, and CR 0.15) and corn starch (1,2, and 3\%; CS 1, CS 2 , and CS 3).

\section{CONCLUSIONS}

Simultaneous fermentation of a yogurt mix and enzymatic hydrolysis of its lactose with Ha-Lactase enabled reduction of the lactose content below the detection level and production of lactose-free yogurt that was subsequently used for frozen yogurt production. Quality and sensory attributes of the products were improved by addition of $\kappa$-carrageenan. The frozen dessert developed had good nutritional value (low fat and low sugar), and due to growing consumer demand for lactose-free products, it may be successfully commercialized.

\section{ACKNOWLEDGMENTS}

This work was supported the Ministry of Agriculture and Rural Development of Portugal and cofinanced by the European Agricultural Fund for Rural Development (EAFRD), through the partnership agreement Portugal2020 - PDR, under the project PDR2020-101-030768:
LACTIES. The work was also partially financed by the Portuguese funds through FCT (Foundation for Science and Technology), project UID/AMB/00681/2019, and by the research potential funds of the Faculty of Food Sciences and Fisheries of West Pomeranian University of Technology, Poland.

\section{REFERENCES}

Abdelazez, A., Z. Muhammad, Q.-X. Zhang, Z.-T. Zhu, H. Abdelmotaal, R. Sami, and X. C. Meng. 2017. Production of a functional frozen yogurt fortified with Bifidobacterium spp. BioMed Res. Int. 2017:6438528. https://doi.org/10.1155/2017/6438528.

Adhikari, K., L. M. Dooley, E. Chambers, and N. Bhumiratana. 2010. Sensory characteristics of commercial lactose-free milks manufactured in the United States. Lebensm. Wiss. Technol. 43:113-118. https://doi.org/10.1016/j.lwt.2009.06.017.

Ahmadi, A., E. Milani, A. Madadlou, S. A. Mortazavi, R. Rezaei Mokarram, and D. Salarbashi. 2014. Synbiotic yogurt ice-cream produced via incorporation of microencapsulated Lactobacillus acidophilus (la-5) and fructooligosaccharide. J. Food Sci. Technol. 51:1568-1574. https://doi.org/10.1007/s13197-012-0679-y.

Akin, M. B., M. S. Akin, and Z. Kirmaci. 2007. Effects of inulin and sugar levels on the viability of yogurt and probiotic bacteria and the physical and sensory characteristics in probiotic ice-cream. Food Chem. 104:93-99. https://doi.org/10.1016/j.foodchem.2006 .11.030.

AOAC International. 1997. Official Methods of Analysis. 16th ed. AOAC International, Gaithersburg, MD.

BahramParvar, M., M. Mazaheri Tehrani, and S. M. A. Razavin. 2013. Effects of a novel stabilizer blend and presence of $\kappa$-carrageenan on some properties of vanilla ice cream during storage. Food Biosci. 3:10-18. https://doi.org/10.1016/j.fbio.2013.05.001.

Brown-Esters, O., P. Mc Namara, and D. Savaiano. 2012. Dietary and biological factors influencing lactose intolerance. Int. Dairy J. 22:98-103. https://doi.org/10.1016/j.idairyj.2011.09.010.

Cais-Sokolińska, D., and J. Pikul. 2006. Use of colour measurement to evaluate yoghurt quality during storage. Ital. J. Food Sci. 18:63-71.

Chen, C. S., C. K. Hsu, and B. H. Chiang. 2002. Optimization of the enzymic process for manufacturing low-lactose milk containing oligosaccharides. Process Biochem. 38:801-808. https://doi.org/10 .1016/S0032-9592(02)00232-7.

El-Nagar, G., G. Clowes, C. M. Tudorică, V. Kuri, and C. S. Brennan. 2002. Rheological quality and stability of yog-ice cream with added inulin. Int. J. Dairy Technol. 55:89-93. https://doi.org/10.1046/j .1471-0307.2002.00042.x.

FAO/WHO (Food and Agriculture Organization of the United Nations/World Health Organization). 2003. Codex Standard for Fermented Milks. Codex Stan 243-2003. 2nd ed. FAO/WHO, Rome, Italy.

Gänzle, M. G., G. Haase, and P. Jelen. 2008. Lactose: Crystallization, hydrolysis and value-added derivatives. Int. Dairy J. 18:685-694. https://doi.org/10.1016/j.idairyj.2008.03.003.

Goff, H. D., and R. W. Hartel. 2004. Ice cream and frozen desserts. Page 499-570 in Handbook of Frozen Foods. Y. A. Hui, P. Cornillon, I. Guerrero Legarretta, M. H. Lim. K. D. Murrell, W.-K. Nip, ed. CRC Press, Boca Raton, FL.

Guinard, J. X., C. Zoumas-Morse, L. Mori, B. Uatoni, D. Panyam, and A. Kilara. 1997. Sugar and fat effects on sensory properties of ice cream. J. Food Sci. 62:1087-1094. https://doi.org/10.1111/j.1365 -2621.1997.tb15044.x.

Guner, A., M. Ardic, A. Keles, and Y. Dogruer. 2007. Production of yogurt ice cream at different acidity. Int. J. Food Sci. Technol. 42:948-952. https://doi.org/10.1111/j.1365-2621.2006.01315.x.

Güven, M., and B. Karaca. 2002. The effects of varying sugar content and fruit concentration on the physical properties of vanilla and fruit ice-cream-type frozen yogurts. Int. J. Dairy Technol. 55:2731. https://doi.org/10.1046/j.1471-0307.2002.00034.x. 
Hameed, M., R. Chandra, and S. Shukla. 2015. The sensory evaluation of frozen yoghurt supplemented by using different concentration of date pulp. European Academic Research 2:14358-14365..

Harju, M., H. Kallioinen, and O. Tossavainen. 2012. Lactose hydrolysis and other conversions in dairy products: Technological aspects. Int. Dairy J. 22:104-109. https://doi.org/10.1016/j.idairyj.2011.09 .011 .

Inoue, K., K. Shiota, and T. Ito. 1998. Preparation and properties of ice cream type frozen yogurt. Int. J. Dairy Technol. 2:44-50. https: //doi.org/10.1111/j.1471-0307.1998.tb02506.x.

IPQ. 1990. Milk and dairy products. Portuguese Standards. Portuguese Institute of Quality (IPPQ), Lisboa, Portugal.

ISO. 2016. Sensory analysis. Methodology. General guidance for establishing a sensory profile. ISO Standard 13299. International Organization for Standardization (ISO), Geneva, Switzerland.

Isik, U., D. Boyacioglu, E. Capanoglu, and D. Nilufer Erdil. 2011. Frozen yogurt with added inulin and isomalt. J. Dairy Sci. 94:16471656. https://doi.org/10.3168/jds.2010-3280.

Lopez, M. C., L. M. Medina, and R. Jordano. 1998. Survival of lactic acid bacteria in commercial frozen yogurt. J. Food Sci. 63:706-708. https://doi.org/10.1111/j.1365-2621.1998.tb15818.x.

Marshall, R. T. 2003. Ice cream and frozen desserts. Pages 1367-1375 in Encyclopaedia of Dairy Sciences. H. Roginski, J. F. Fuquay, P. F. Fox, ed. Academic Press, London, UK.

Messia, M. C., T. Candigliota, and E. Marconi. 2007. Assessment of quality and technological characterization of lactose-hydrolyzed milk. Food Chem. 104:910-917. https://doi.org/10.1016/j .foodchem.2006.12.045

Milani, E., and A. Koocheki. 2011. The effects of date syrup and guar gum on physical, rheological and sensory properties of low fat frozen yoghurt dessert. Int. J. Dairy Technol. 64:121-129. https://doi .org/10.1111/j.1471-0307.2010.00631.x

Moeenfard, M., and M. M. Tehrani. 2008. Effect of some stabilizers on the physicochemical and sensory properties of ice cream type frozen yogurt. Am. Euras. J. Agric. Environ. Sci. 5:584-589.

Moreira, T. C., A. Transfeld da Silva, C. Fagundes, S. M. Rodrigues Ferreira, L. M. Bileski Cândido, M. Passos, and C. C. Hecke
Krüger. 2017. Elaboration of yogurt with reduced level of lactose added of carob (Ceratonia siliqua L.). Lebensm. Wiss. Technol. 76:326-329. https://doi.org/10.1016/j.lwt.2016.08.033.

Pei, Z. J., and K. A. Schmidt. 2010. Ice cream: Foam formation and stabilization-A review. Food Rev. Int. 26:122-137. https://doi .org/10.1080/87559120903564472.

Raza, A., S. Iqbal, A. Ullah, and M. I. Khan. 2018. Enzymatic conversion of milk lactose to prebiotic galacto-oligosaccharides to produce low lactose yogurt. J. Food Process. Preserv. 42:e13586. https://doi.org/10.1111/jfpp.13586.

Rezaei, R., M. Khomeiri, M. Aalami, and M. Kashaninejad. 2014. Effect of inulin on the physicochemical properties, flow behavior and probiotic survival of frozen yogurt. J. Food Sci. Technol. 51:2809 2814. https://doi.org/10.1007/s13197-012-0751-7.

Singla, V., and S. Chakkaravarthi. 2017. Applications of prebiotics in food industry: A review. Food Sci. Technol. Int. 23:649-667. https: //doi.org/10.1177/1082013217721769

Soukoulis, C., I. Chandrinos, and C. Tzia. 2008. Study of the functionality of selected hydrocolloids and their blends with $\kappa$-carrageenan on storage quality of vanilla ice cream. Lebensm. Wiss. Technol. 41:1816-1827. https://doi.org/10.1016/j.lwt.2007.12.009.

Stampanoni, K. C. R., P. Piccinali, and S. Sigrist. 1996. The influence of fat, sugar and non-fat milk solids on selected taste, flavor and textural parameters of a vanilla ice-cream. Food Qual. Prefer. 7:69-79. https://doi.org/10.1016/0950-3293(95)00038-0.

Vega, C., and H. D. Goff. 2005. Phase separation in soft-serve ice cream mixes: Rheology and microstructure. Int. Dairy J. 15:249254. https://doi.org/10.1016/j.idairyj.2004.07.007.

Vénica, C. I., I. V. Wolf, C. V. Bergamini, and M. C. Perotti. 2016. Influence of lactose hydrolysis on galacto-oligosaccharides, lactose, volatile profile and physicochemical parameters of different yogurt varieties. J. Sci. Food Agric. 96:4929-4939. https://doi.org/ $10.1002 /$ jsfa. 7870.

Wolf, I. V., C. I. Vénica, and M. C. Perotti. 2015. Effect of reduction of lactose in yogurts by addition of $\beta$-galactosidase enzyme on volatile compound profile and quality parameters. Int. J. Food Sci. Technol. 50:1076-1082. https://doi.org/10.1111/ijfs.12745. 